\title{
Genetic Analysis of Salt Tolerance in Arabidopsis: Evidence for a Critical Role of Potassium Nutrition
}

\author{
J ian-Kang Zhu, ${ }^{1} \mathrm{~J}$ iping Liu, and Liming Xiong \\ Department of Plant Sciences, University of Arizona, Tucson, Arizona 85721
}

\begin{abstract}
A large genetic screen for sos (for salt overly sensitive) mutants was performed in an attempt to isolate mutations in any gene with an sos phenotype. Our search yielded 28 new alleles of sos1, nine mutant alleles of a newly identified locus, SOS2, and one allele of a third salt tolerance locus, SOS3. The sos2 mutations, which are recessive, were mapped to the lower arm of chromosome $V, \sim 2.3$ centimorgans away from the marker PHYC. Growth measurements demonstrated that sos 2 mutants are specifically hypersensitive to inhibition by $\mathrm{Na}^{+}$or $\mathrm{Li}^{+}$and not hypersensitive to general osmotic stresses. Interestingly, the SOS2 locus is also necessary for $\mathrm{K}^{+}$nutrition because sos 2 mutants were unable to grow on a culture medium with a low level of $\mathrm{K}^{+}$. The expression of several salt-inducible genes was superinduced in sos 2 plants. The salt tolerance of sos1, sos2, and $\operatorname{sos} 3$ mutants correlated with their $\mathrm{K}^{+}$tissue content but not their $\mathrm{Na}^{+}$ tissue content. Double mutant analysis indicated that the SOS genes function in the same pathway. Based on these results, a genetic model for salt tolerance mechanisms in Arabidopsis is presented in which SOS1, SOS2, and SOS3 are postulated to encode regulatory components controlling plant $\mathrm{K}^{+}$nutrition that in turn is essential for salt tolerance.
\end{abstract}

\section{INTRODUCTION}

Excessive salt accumulation in soils affects the productivity of one-third of the world's limited arable land (Epstein et al., 1980). Much effort has been devoted toward understanding the mechanisms of plant salt tolerance with the eventual goal of improving the performance of crop plants in saline soils (Binzel and Reuveni, 1994). Equally important, these efforts continue to yield valuable knowledge about plant osmotic stress responses as well as cellular ion homeostasis (Bohnert et al., 1995; Niu et al., 1995; Zhu et al., 1997).

A widely used approach to unravel plant salt tolerance mechanisms has been to identify cellular processes and genes whose activity or expression is regulated by salt stress (reviewed in Hasegawa et al., 1987; Cushman et al., 1990; Skriver and Mundy, 1990; Bray, 1993; Bohnert et al., 1995; Zhu et al., 1997). The underlying assumption is that salt-regulated processes and genes likely function in salt tolerance. Although this correlative approach has contributed to our appreciation of the complex nature of plant responses to salinity, it has failed, to a large extent, to establish salt tolerance determinants (Zhu et al., 1997). There are numerous documented changes in cellular activities in higher plants in response to salt stress. Such changes include, for example, cell wall alterations (I ones and Turner, 1978; Iraki et al., 1989), declines in photosynthesis (Seemann and Critchley, 1985; Locy et al., 1996), protein synthesis (Singh

\footnotetext{
${ }^{1}$ To whom correspondence should be addressed. E-mail jkzhu@ag.
} arizona.edu; fax 520-621-7186. et al., 1985; Hurkman and Tanaka, 1987), and potassium content (Rains, 1972; Greenway and Munns, 1980), and increases in $\mathrm{Na}^{+}$(Watad et al., 1983; Serrano and Gaxiola, 1994) and organic solutes, such as proline, glycinebetaine, and polyols (Greenway and Munns, 1980; Yancey et al., 1982; McCure and Hanson, 1990; Delauney and Verma, 1993). Although data correlating these cellular activities with salt tolerance abound, it has been difficult to ascertain which of the physiological and metabolic changes is required for salt tolerance. Similarly, despite the correlation of expression of numerous genes with salt stress (Cushman et al., 1990; Bray, 1993; Serrano and Gaxiola, 1994), very few genes are known to be essential for salt tolerance (Bray, 1993; Serrano and Gaxiola, 1994; Zhu et al., 1997). It has become evident that although some of these changes are adaptive and lead to salt tolerance, many are probably direct or indirect consequences of salt stress damage.

An alternative approach to identifying genes and cellular processes crucial for plant salt tolerance is to select for mutants with impaired salt tolerance (Wu et al., 1996). We have conducted a mutational analysis of plant responses to salt stress in the glycophyte Arabidopsis. Our initial efforts resulted in the isolation of several sos (for salt overly sensitive) mutants in one complementation group, SOS1 (W. 1996). Analysis of these mutants showed that sos 1 is defective in high-affinity potassium uptake, suggesting that potassium acquisition is a cellular process essential for salt tolerance in glycophytic species (Wu et al., 1996). Under 
$\mathrm{NaCl}$ stress, sos1 mutants accumulate more proline (Liu and Zhu, 1997a) but absorb less $\mathrm{Na}^{+}$as well as less $\mathrm{K}^{+}$(Ding and Zhu, 1997). Several salt-inducible genes show increased expression in sos1 mutants under salt stress (Liu and Zhu, 1997a). We have since completed a large-scale screening ( $\sim 260,000$ plants) in an attempt to identify all genetic loci mutations in which can result an sos phenotype. Altogether, 42 sos mutants have been recovered. With these 42 sos mutants, it is now possible to address questions such as what other loci are also essential for plant salt tolerance and in what cellular processes do they function to control salt tolerance.

In this study, we summarize the screening results and present the characterization of mutants that define a new salt tolerance locus, SOS2. Analysis of all the sos mutants provided evidence suggesting that potassium nutrition, rather than sodium homeostasis or osmolyte accumulation, is most critical for salt tolerance in the glycophytic model plant Arabidopsis.

\section{RESULTS}

\section{Identification of the SOS2 Locus}

Table 1 summarizes our screens for sos mutants. Altogether, 267,000 plants from either ethyl methanesulfonate- or fastneutron-mutagenized $M_{2}$ seeds or from T-DNA insertion lines were screened using the root-bending assay (Wu et al., 1996; Figure 1). The more tedious single seedling transfer method for the root-bending assay was used because in our hands the rapid vertical-mesh-transfer method (Murphy and Taiz, 1995) was not as dependable. Approximately 156,000 seedlings were screened on $50 \mathrm{mM} \mathrm{NaCl}$ medium; the rest were screened using $75 \mathrm{mM} \mathrm{NaCl}$. In total, 42 independent sos mutants were identified.

All mutants were backcrossed to their respective wildtype backgrounds. Analysis of the $F_{1}$ progeny showed that all of the mutations are recessive. The $F_{2}$ progeny resulting from the backcrosses showed approximately a 3:1 segregation ratio of wild type to mutant ( $\chi^{2}$ test, $\left.P>0.05\right)$. Thus, all of the mutants are caused by single nuclear mutations. Allelism tests showed that the mutants fall into three complementation groups. Of the 42 sos mutants, 32, including four that were reported earlier (Wu et al., 1996), were found to be alleles of SOS1 (data not shown). Except that one is not as sensitive to $\mathrm{NaCl}$ as sos1-1, the sos phenotype of all new sos 1 alleles appears as strong as sos1-1. One mutant defines the SOS3 locus (Liu and Zhu, 1997b). The remaining nine alleles define a new locus, SOS2. There is no substantial difference in $\mathrm{NaCl}$ sensitivity among the nine sos2 alleles. The recessivity and complementation results of sos 2 mutants are presented in Table 2 . In the allelism tests, all nine sos 2 alleles were crossed to sos 1-1 and sos3-1, although only data on a representative allele (i.e., sos2-1) are presented in Table 2 . For the many sos 1 alleles, in most cases only the representative sos 1-1 mutant was used to determine their allelism.

All subsequent physiological and phenotypic studies were performed on mutants that had been backcrossed to the wild type at least once. Figure 1 compares the phenotypes of sos 1-1, sos2-1, and sos3-1 seedlings in the root-bending assay. All three mutants as well as wild-type seedlings grew relatively well and appeared healthy on control MurashigeSkoog (MS) medium (Murashige and Skoog, 1962) without $\mathrm{NaCl}$ supplementation (Figure 1A). On $50 \mathrm{mM} \mathrm{NaCl}$, the growth of sos1-1 and sos2-1 was substantially inhibited. In comparison, the growth of wild-type and sos3-1 seedlings was much less inhibited by $50 \mathrm{mM} \mathrm{NaCl}$ (Figure 1B). On 100 $\mathrm{mM} \mathrm{NaCl}$, wild-type seedlings still grew, albeit not very well.

Table 1. Summary of sos Mutant Screening

\begin{tabular}{|c|c|c|c|c|c|c|}
\hline Mutagen & $\begin{array}{l}\text { No. of } M_{1} \text { or } T_{1} \\
\text { Lines Screened }\end{array}$ & $\begin{array}{l}\text { No. of } \mathrm{M}_{2} \text { or } \mathrm{T}_{4} \\
\text { Plants Screened }\end{array}$ & $\begin{array}{l}{[\mathrm{NaCl}] \text { in Screening }} \\
\text { Media (mM) }\end{array}$ & $\begin{array}{l}\text { No. of } \\
\text { Mutants }\end{array}$ & $\begin{array}{l}\text { Types of } \\
\text { Mutants }\end{array}$ & Reference \\
\hline \multirow[t]{5}{*}{ EMS $^{a}$} & 6,500 & 50,000 & 50 & 4 & 4 sos 1 & Wu et al. (1996) \\
\hline & 5,000 & 30,000 & 50 & 14 & 9 sos 1 & This study \\
\hline & & & & & $5 \operatorname{sos} 2$ & \\
\hline & 3,000 & 25,000 & 75 & 7 & 4 sos 1 & This study \\
\hline & & & & & $3 \operatorname{sos} 2$ & \\
\hline \multirow[t]{4}{*}{ Fast neutron } & 2,000 & 16,000 & 50 & 6 & $5 \operatorname{sos} 1$ & This study \\
\hline & & & & & $1 \operatorname{sos} 2$ & \\
\hline & 2,000 & 16,000 & 75 & 7 & $6 \operatorname{sos} 1$ & This study; Liu and \\
\hline & & & & & $1 \operatorname{sos} 3$ & Zhu (1997b) \\
\hline \multirow[t]{2}{*}{ T-DNA } & 6,000 & 60,000 & 50 & 1 & 1 sos 1 & This study \\
\hline & 5,000 & 70,000 & 75 & 3 & $3 \operatorname{sos} 1$ & This study \\
\hline
\end{tabular}

aEMS, ethyl methanesulfonate. 
A

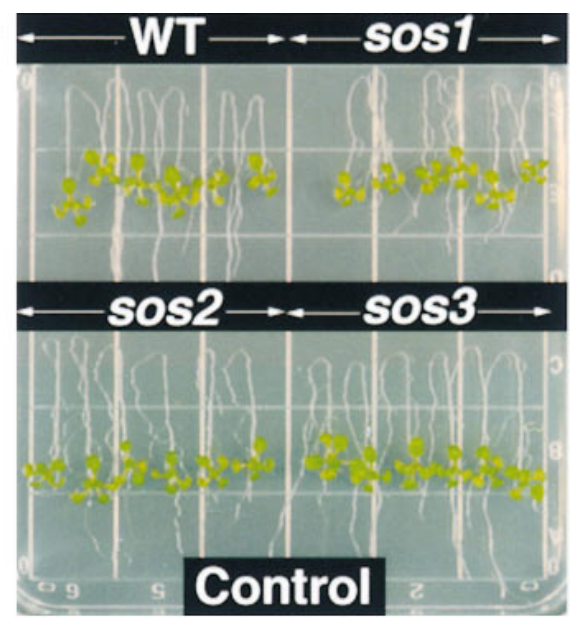

B

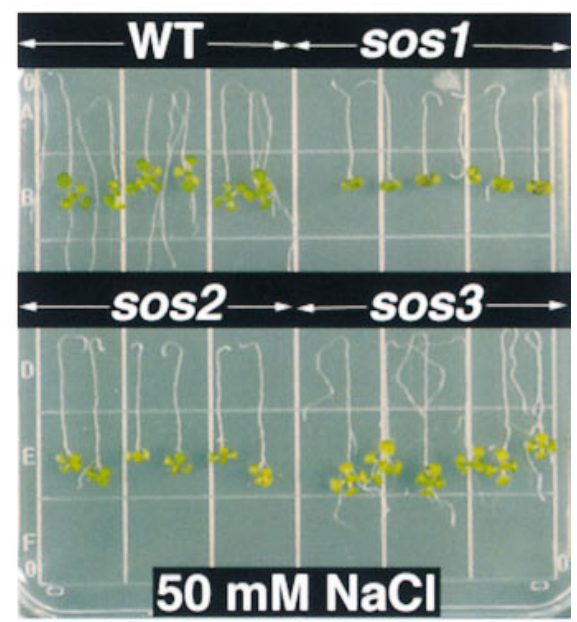

C

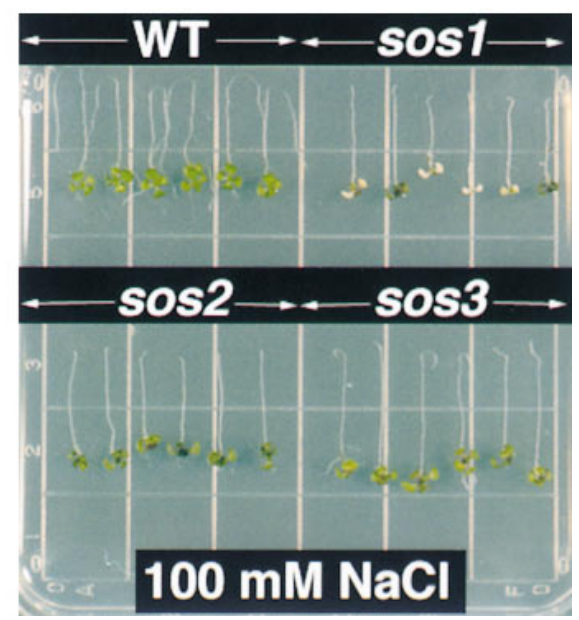

However, $100 \mathrm{mM} \mathrm{NaCl}$ exhibited complete growth inhibition on sos2-1 and near-complete growth inhibition on sos3-1, whereas sos1-1 seedlings were killed by this high level of $\mathrm{NaCl}$ stress (Figure $1 \mathrm{C}$ ).

To genetically map the sos2 mutation, we crossed homozygous sos2-2 plants in the Columbia glabrous1 ( $g l 1)$ background to plants of the Landsberg erecta background. The sos2-2 allele was chosen for mapping because it is a fastneutron allele and virtually identical to sos2-1 in phenotype. We selected 624 sos mutants from the resulting $F_{2}$ population and extracted genomic DNA from each of these plants. By using the mapping methods of Bell and Ecker (1994), sos 2 was found to be linked to the simple sequence length polymorphisms (SSLP) marker nga76 on chromosome V. It was further determined that sos 2 is linked more tightly to the cleaved amplified polymorphic sequence marker PHYC (Konieczny and Ausubel, 1993) on the lower arm of chromosome V. Of the 1248 chromosomes surveyed, only 29 recombinants were found, indicating that the sos2 mutation is $\sim 2.3$ centimorgans away from PHYC (Figure 2 ). In comparison, the sos3 mutation was mapped to a different segment of chromosome $V$ near the SSLP marker nga139 (Liu and Zhu, 1997b), and the sos1 mutation was mapped to chromosome II (Wu et al., 1996).

\section{sos2 Plants Are Hypersensitive to $\mathrm{Na}^{+}$and $\mathrm{Li}^{+}$but Not to $\mathrm{Cs}^{+}$and Mannitol Stresses}

The responses of sos2- 1 seedlings to various salts and mannitol were analyzed to determine whether sos2-1 is hypersensitive to general osmotic stress or to specific ions. Figures $3 \mathrm{~A}$ and $3 \mathrm{~B}$ show that sos2-1 mutant plants are hypersensitive to $\mathrm{NaCl}$ but not to $\mathrm{KCl}$. The concentration of $\mathrm{NaCl}$ that decreased the root growth rate by $50 \%$ relative to medium without salt $\left(I_{50}\right)$ was estimated. The $I_{50}$ concentrations for sos2- 1 seedlings and the wild-type seedlings were $\sim 10$ and $100 \mathrm{mM}$, respectively. In comparison, the $I_{50}$ values for sos $1-1$ and sos3- 1 are $\sim 4 \mathrm{mM}$ (Wu et al., 1996) and $40 \mathrm{mM}$ (Liu and Zhu, 1997b), respectively. This difference in sensitivity to $\mathrm{NaCl}$ inhibition among sos mutants is also seen in Figure 1. Growth analysis of sos2-1 on $\mathrm{LiCl}$ indicated that sos2-1 was also hypersensitive to $\mathrm{Li}^{+}$, a toxic cation closely related to $\mathrm{Na}^{+}$(Figure 3C). Interestingly, although $\mathrm{Cs}^{+}$is also a toxic cation related to $\mathrm{Na}^{+}$, sos2-1 was not hypersensitive to $\mathrm{Cs}^{+}$stress (Figure 3D).

Figure 4 shows that sos2- 1 was not hypersensitive to osmotic stress caused by mannitol. In contrast, sos 1-1 exhibited hypersensitivity to mannitol stress at low concentrations $(<150$ $\mathrm{mM}$; Figure 4). At higher mannitol concentrations (150 to
Figure 1. Comparison of Salt Sensitivity in sos Mutants on Vertical Plates by Using the Root-Bending Assay.

Five-day-old seedlings were transferred from normal MS medium to MS media supplemented with different concentrations of $\mathrm{NaCl}$, and the seedlings (with roots upside down) were allowed to grow for 7 days. WT, wild type.
(A) Control (no NaCl).

(B) $50 \mathrm{mM} \mathrm{NaCl}$.

(C) $100 \mathrm{mM} \mathrm{NaCl}$. 
Table 2. Genetic Analysis of sos2 Mutants

\begin{tabular}{|c|c|c|c|c|}
\hline Crosses & Generation & Total Seedlings Tested & Resistanta & Sensitive \\
\hline \multirow[t]{2}{*}{ SOS2-1/SOS2-1 × sos2-1/sos2-1b } & $\mathrm{F}_{1}$ & 120 & 120 & 0 \\
\hline & $\mathrm{F}_{2}$ & 429 & 322 & 107 \\
\hline $\operatorname{sos} 2-1 / \operatorname{sos} 2-1 \times \operatorname{sos} 1-1 / \operatorname{sos} 1-1^{b}$ & $\mathrm{~F}_{1}$ & 105 & 105 & 0 \\
\hline $\operatorname{sos} 2-1 / \operatorname{sos} 2-1 \times \operatorname{sos} 3-1 / \operatorname{sos} 3-1^{b}$ & $\mathrm{~F}_{1}$ & 126 & 126 & 0 \\
\hline sos $2-2 /$ sos $2-2 \times \operatorname{sos} 2-1 / \operatorname{sos} 2-1$ & $\mathrm{~F}_{1}$ & 101 & 0 & 101 \\
\hline $\operatorname{sos} 2-3 / \operatorname{sos} 2-3 \times \operatorname{sos} 2-1 / \operatorname{sos} 2-1$ & $\mathrm{~F}_{1}$ & 127 & 0 & 127 \\
\hline $\operatorname{sos} 2-4 / \operatorname{sos} 2-4 \times \operatorname{sos} 2-3 / \operatorname{sos} 2-3$ & $\mathrm{~F}_{1}$ & 38 & 0 & 38 \\
\hline $\operatorname{sos} 2-5 / \operatorname{sos} 2-5 \times \operatorname{sos} 2-3 / \operatorname{sos} 2-3$ & $\mathrm{~F}_{1}$ & 61 & 0 & 61 \\
\hline $\operatorname{sos} 2-6 / \operatorname{sos} 2-6 \times \operatorname{sos} 2-2 / \operatorname{sos} 2-2$ & $\mathrm{~F}_{1}$ & 31 & 0 & 31 \\
\hline $\operatorname{sos} 2-7 / \operatorname{sos} 2-7 \times \operatorname{sos} 2-2 / \operatorname{sos} 2-2$ & $\mathrm{~F}_{1}$ & 51 & 0 & 51 \\
\hline $\operatorname{sos} 2-8 / \operatorname{sos} 2-8 \times \operatorname{sos} 2-2 / \operatorname{sos} 2-2$ & $\mathrm{~F}_{1}$ & 30 & 0 & 30 \\
\hline $\operatorname{sos} 2-9 / \operatorname{sos} 2-9 \times \operatorname{sos} 2-2 / \operatorname{sos} 2-2$ & $\mathrm{~F}_{1}$ & 10 & 0 & 10 \\
\hline
\end{tabular}

a Resistance or sensitivity was determined in the root-bending assay by using $100 \mathrm{mM} \mathrm{NaCl}$.

b Similar results were obtained when all other sos2 alleles were crossed with the wild type, sos1-1, and sos3-1.

$500 \mathrm{mM}$ ), sos1-1 was also not hypersensitive (Figure 4). Taken together, the results in Figures 3 and 4 indicate that the sos2-1 mutation does not cause a defective osmotic stress response. Rather, the defect is restricted to $\mathrm{Na}^{+}$and $\mathrm{Li}^{+}$tolerance. Therefore, sos2-1 is likely to be defective in ion homeostasis.

\section{sos2-1 Seedlings Are Unable to Grow on Low-Potassium Culture Media}

Because sos1 and sos3 mutants are unable to grow on culture media containing low levels of potassium, we deter-

Chromosome II

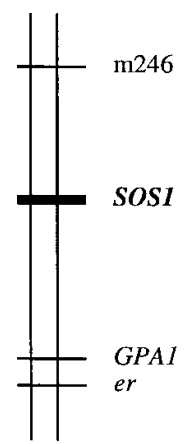

\section{Chromosome V}

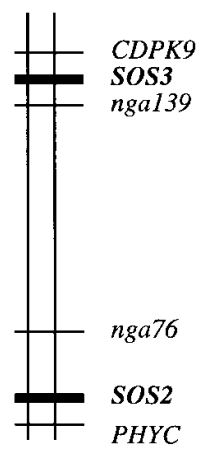

Figure 2. Map Positions of SOS Loci.

SOS2 and SOS3 (Liu and Zhu, 1997b) are both mapped on chromosome V; SOS1 (Wu et al., 1996) is located on chromosome II. mined whether sos2-1 plants are similarly affected. Wildtype and sos2-1 seedlings grown on MS medium ( $\sim 20 \mathrm{mM}$ $\mathrm{K}^{+}$) were transferred to modified MS media containing various levels of $\mathrm{K}^{+}$(Liu and Zhu, 1997b). Root growth was measured 1 week after the transfer. Root growth in the first day was not included so that the effect of residual $\mathrm{K}^{+}$carried from the seedlings transferred from the MS medium was minimized. Figure 5 shows that wild-type and sos2- 1 mutant seedlings had very different $\mathrm{K}^{+}$requirements for maximal growth. Despite their poor growth in the absence of added $\mathrm{K}^{+}$, inclusion of $100 \mu \mathrm{M} \mathrm{K}+$ in the medium was enough to produce near-maximal growth for wild-type seedlings (Figure 5 ). In contrast, sos2-1 seedlings required substantially more $\mathrm{K}^{+}$for growth; $10 \mathrm{mM} \mathrm{K}+$ was necessary for sos2-1 to achieve $80 \%$ of maximal growth (Figure 5 ). For comparison, sos3- 1 seedlings require $1 \mathrm{mM} \mathrm{K}^{+}$for $80 \%$ of maximal growth (Liu and Zhu, 1997b), and sos1-1 seedlings require $\geqslant 20 \mathrm{mM} \mathrm{K}^{+}$for normal growth (Wu et al., 1996). At least $50 \mathrm{mM} \mathrm{K}^{+}$was necessary for maximal growth for both sos2-1 (Figure 5) and sos1-1 seedlings (Liu and Zhu, 1997b). The growth data on high concentrations of $\mathrm{K}^{+}$(Figure 5 ) differ somewhat from those in Figure $3 \mathrm{~B}$ because the base growth media used in this case were not based on MS but its modified version (Liu and Zhu, 1997b), which contains potassium-free $1 / 20$ strength MS major salts and $1 \times M S$ minor salts.

${ }^{86} \mathrm{Rb}^{+}$tracer uptake experiments demonstrated that sos $1-1$ seedlings have a defect in $\mathrm{K}^{+}$uptake (Wu et al., 1996). Similar measurements have failed to detect any substantial difference in $\mathrm{K}^{+}$uptake between wild-type and sos2-1 (data not shown) or sos3-1 (Liu and Zhu, 1997b) seedlings or excised roots. The growth defect of sos3-1 but not sos1-1 seedlings on low $\mathrm{K}^{+}$can be rescued by increased external $\mathrm{Ca}^{2+}(\mathrm{Liu}$ and Zhu, 1997b). High external $\mathrm{Ca}^{2+}$ levels up to $10 \mathrm{mM}$ were not able to rescue the growth of sos2-1 seedlings on low $\mathrm{K}^{+}$(data not shown). 


\section{$\mathrm{NaCl}$ Sensitivity of sos Mutants Correlates with Cellular $\mathrm{K}^{+}$but Not $\mathrm{Na}^{+}$Content}

The $\mathrm{K}^{+}$and $\mathrm{Na}^{+}$contents of wild-type, sos1-1, sos2-1, and sos3- 1 seedlings were measured after being treated with 50 $\mathrm{mM} \mathrm{NaCl}$ for $24 \mathrm{hr}$. Consistent with previous observations ( $\mathrm{Wu}$ et al., 1996; Ding and Zhu, 1997; Liu and Zhu, 1997b), sos1-1 seedlings treated with $\mathrm{NaCl}$ were found to have lower $\mathrm{Na}^{+}$as well as $\mathrm{K}^{+}$content, whereas sos3-1 seedlings accumulated less $\mathrm{K}^{+}$and more $\mathrm{Na}^{+}$than did the wild type (Figures $6 \mathrm{~A}$ and $6 \mathrm{~B})$. sos2- 1 seedlings treated with $\mathrm{NaCl}$ also had lower $\mathrm{K}^{+}$levels than did the wild type (Figure $6 A$ ). Interestingly, the $K^{+}$level in $\mathrm{NaCl}$-treated wild-type and sos seedlings (Figure 6A) appears to correlate with their salt tolerance (Figure $6 \mathrm{C}$ ).

$\mathrm{Na}^{+}$content in sos2-1 seedlings treated with $50 \mathrm{mM} \mathrm{NaCl}$ was higher than that in sos1-1, sos3-1, or the wild type (Figure $6 \mathrm{~B})$. The results indicate that salt sensitivity of the sos mutants is not correlated with their cellular $\mathrm{Na}^{+}$content.

\section{sos2 Mutations Cause Selective Superinduction of Salt-Induced Gene Expression}

Because the SOS2 locus is essential for salt tolerance, we were interested in determining the role of this locus in the regulation of gene expression by salt stress. Four salt-inducible genes were chosen for this purpose. The RD29A gene encodes a protein with potential protective function during desiccation (Yamaguchi-Shinozaki and Shinozaki, 1993). The P5CS gene encodes the enzyme $\Delta^{1}$-pyrroline-5-carboxylate synthetase involved in proline biosynthesis (Delauney and Verma, 1990; Hu et al., 1992). AtMYB and AtPLC, which encode a MYB-related transcription factor and phospholipase $C$, respectively, have been proposed to play roles in osmotic signal transduction (Urao et al., 1993; Hirayama et al., 1995). Expression of each of the four genes was induced by $\mathrm{NaCl}$ stress in both wild-type and sos2-1 seedlings (Figure 7). However, the induction of AtMYB and AtPLC expression in sos2-1 was much
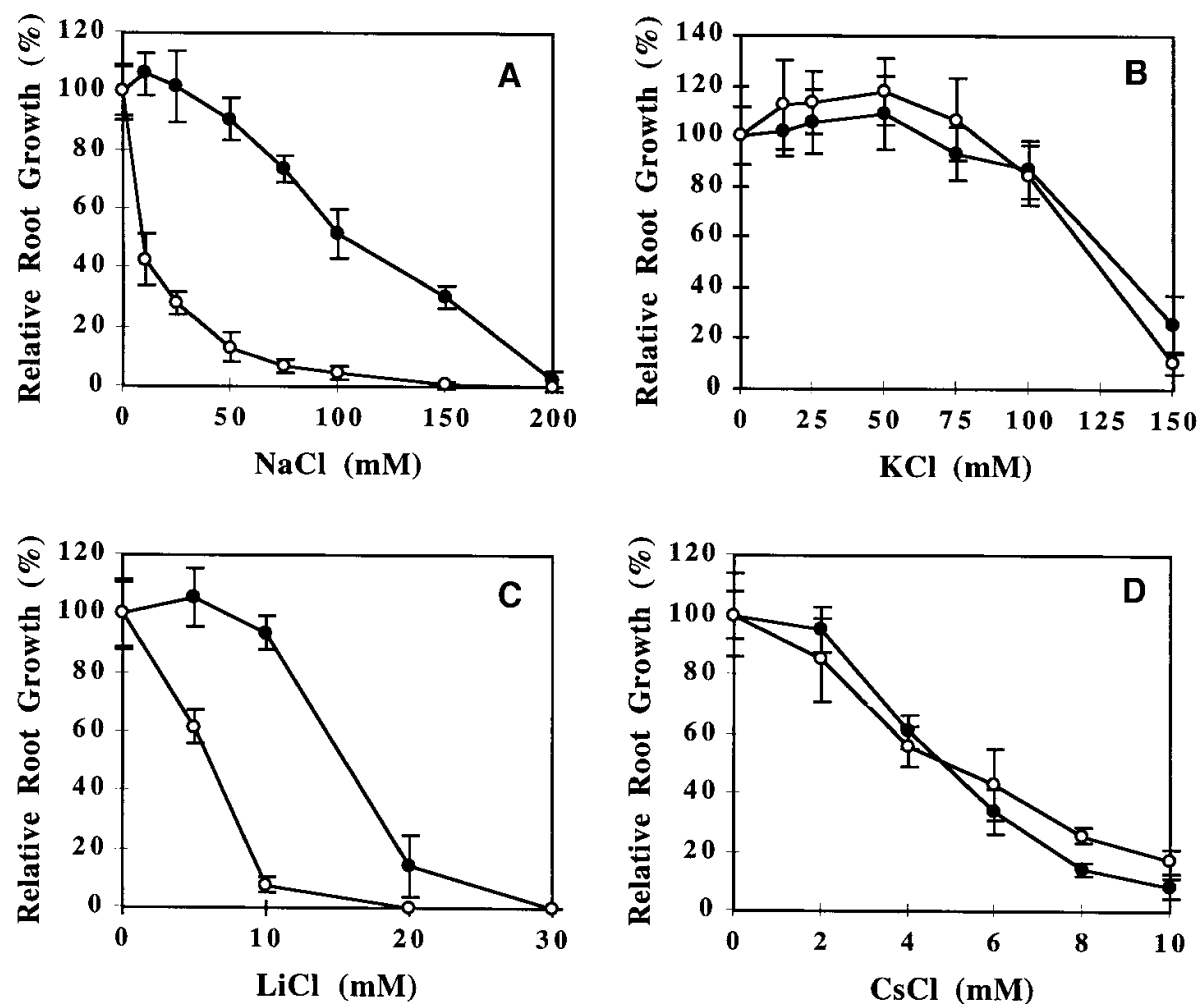

Figure 3. Sensitivity of sos2 Seedlings to Various Salts.

Four-day-old seedlings were transferred to MS medium or MS media supplemented with various concentrations of $\mathrm{NaCl}, \mathrm{KCl}, \mathrm{LiCl}$, or CsCl. Root elongation after 7 days is presented as a percentage relative to elongation on MS medium. Filled circles, wild type; open circles, sos2. Error bars represent the standard deviation $(n=15)$.

(A) Sensitivity to $\mathrm{NaCl}$.

(B) Senstivity to $\mathrm{KCl}$.

(C) Sensitivity to $\mathrm{LiCl}$.

(D) Sensitivity to $\mathrm{CsCl}$. 


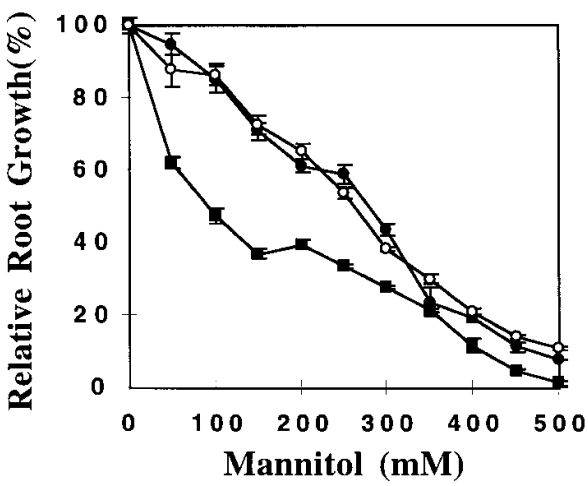

Figure 4. sos1 Mutants but Not sos2 Mutants Are Hypersensitive to Mannitol Stress.

Four-day-old seedlings were transferred to MS medium or media supplemented with various concentrations of mannitol. Root elongation after 7 days is presented as the percentage relative to that on MS medium. Filled circles, wild type; filled squares, sos1; open circles, sos2. Error bars represent the standard deviation $(n=15)$.

higher than in the wild type (Figure 7). The expression of P5CS was slightly higher in sos2-1 compared with that in the wild type. No substantial difference in the expression of RD29A was found between sos2-1 and the wild type (Figure 7).

The expression of AtMYB and RD29A in sos2-1 is similar to that seen in sos 1-1 plants (Liu and Zhu, 1997a). P5CS has a higher level of expression in sos 1-1 compared with sos2-1 and the wild type. The greatest difference between sos2-1 and sos1-1 mutants is in the expression of AtPLC because sos1-1 and the wild-type plants have similar levels of AtPLC expression. The data suggest that the SOS2 locus plays a negative role in the expression of AtMYB, AtP LC, and P5CS but not of RD29A.

\section{Genetic Interaction between sos2 and sos1 Mutations}

sos1, sos2, and sos3 mutants exhibited similar phenotypes in that they are all hypersensitive to $\mathrm{Na}^{+}$and $\mathrm{Li}^{+}$and are not capable of growing on low- $\mathrm{K}^{+}$culture media. Thus, the three SOS genes may function in the same pathway that regulates $\mathrm{K}^{+}$acquisition or utilization and salt tolerance. Double mutant analysis indicated that sos 1 is epistatic to sos3 (Liu and Zhu, 1997b). To determine the epistatic relationship between sos 1 and sos 2 mutations, we constructed sos1 sos2 double mutants.

The response of the sos1 sos2 double mutant to $\mathrm{NaCl}$ inhibition was similar to that of sos1. This can be demonstrated conveniently when sos1-1, sos2-1, and sos1 sos2 seedlings were exposed for 1 week to an agar medium containing $100 \mathrm{mM} \mathrm{NaCl}$ (Figure 8). Only $~ 38 \%$ of sos1 seedlings survived the treatment, whereas none of the sos2 seedlings were killed. Approximately $42 \%$ of sos 1 sos 2 dou- ble mutants survived the same treatment. Furthermore, the growth of sos1 sos2 double mutants on 50 or $100 \mathrm{mM} \mathrm{NaCl}$ was virtually identical to that seen in sos 1 (data not shown). The data indicate that the two mutations are not additive and support the notion that the SOS genes function in a linear pathway.

\section{DISCUSSION}

\section{SOS2 Locus Is Required for Both Salt Tolerance and Potassium Nutrition}

The SOS2 locus is defined by nine independent sos mutants. The nine sos 2 alleles are all recessive and confer salt hypersensitivity when present in the homozygous state. The salt hypersensitivity phenotype of sos 2 is a basic cellular trait and is displayed by the mutants at every developmental stage (data not shown). In fact, calli derived from sos2 seeds are also hypersensitive to $\mathrm{NaCl}$ (data not shown). sos2 seedlings were not able to grow on low- $\mathrm{K}+$ culture medium, which reveals an essential role of the SOS2 gene in potassium nutrition.

sos2 mutants are similar to sos 1 and sos 3 mutants in that they are all hypersensitive to $\mathrm{Na}^{+}$and $\mathrm{Li}^{+}$stresses and incapable of growing on low- $\mathrm{K}^{+}$culture medium. However, sos 2 mutants are also different from sos 1 and sos3 in several ways. sos 2 plants were not as sensitive to $\mathrm{Na}^{+}$as were sos 1

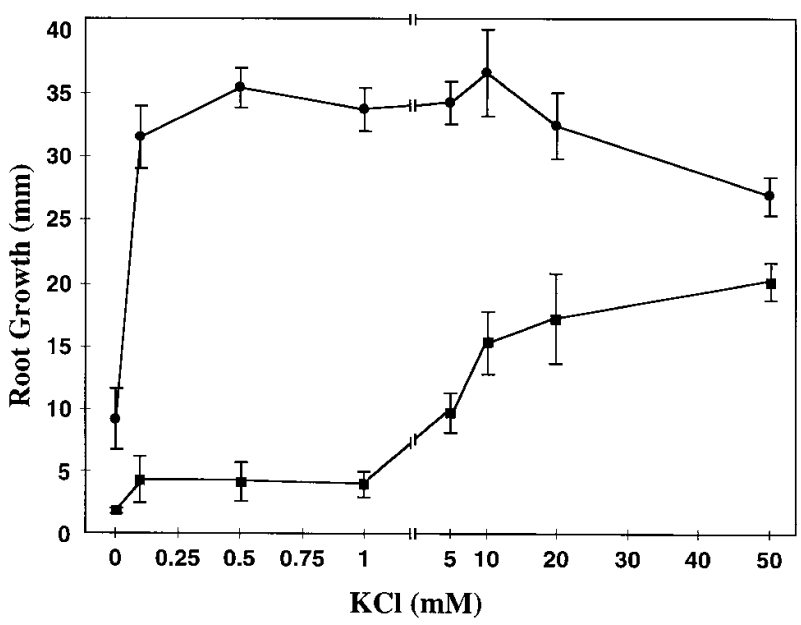

Figure 5. Optimal Growth of sos2 Requires Increased External $\mathrm{K}^{+}$in the Culture Media.

Root elongation 7 days after the transfer of seedlings to culture media containing various levels of $\mathrm{K}^{+}$was measured. Wild-type seedlings (filled circles) reached near-maximal growth at a very low $\mathrm{K}^{+}$ concentration $(100 \mu \mathrm{M} \mathrm{K})$. sos2 seedlings (filled squares) required as high as $50 \mathrm{mM} \mathrm{K}$ for maximal growth. Error bars represent the standard deviation $(n=15)$. 
plants (Figures 1, 6C, and 8). sos2 plants were not hypersensitive to mannitol stress, whereas sos 1 plants were hypersensitive to low to moderate levels $(<150 \mathrm{mM})$ of mannitol (Figure 4). Growth of sos1 mutants had a higher requirement for $\mathrm{K}^{+}$than did sos2 (Figure 5). $\mathrm{K}^{+}$deficiency in sos 2 mutants was not as severe as in sos 1 under the same level of $\mathrm{NaCl}$ stress (Figure 6A). Although the $\mathrm{Na}^{+}$content in $\mathrm{NaCl}$-treated sos 1 seedlings was lower than that of the wild type, sos2 had a slightly higher $\mathrm{Na}^{+}$content than did the wild type. Finally, SOS2 but not SOS1 is a negative regulator of AtPLC gene expression.

Compared with sos3, sos2 is more sensitive to $\mathrm{Na}^{+}$(Figure 1). Growth of sos2 seedlings required more $\mathrm{K}^{+}$than did sos 3 plants. sos 2 also had a lower $\mathrm{K}^{+}$content than did sos 3 when treated with $\mathrm{NaCl}$. Most notably, high $\mathrm{Ca}^{2+}$ concentration cannot restore growth of sos 2 seedlings on low- $\mathrm{K}^{+} \mathrm{cul}-$ ture medium as it does for sos3.

It is interesting that the sos 2 mutation also resulted in the superinduction of some salt-regulated genes. This appears not to be a simple consequence of more severe growth inhibition and damage caused by $\mathrm{NaCl}$ stress in the mutant. Increased inducibility was seen mainly in the AtPLC and AtMYB genes, which have been proposed to be intermediate components in stress signaling pathways. It is possible that SOS2 encodes a regulatory component that cross-talks with signaling pathways that control the expression of AtPLC, AtMYB, and P5CS.

\section{Which Is More Detrimental to Plants under Salt Stress: Higher Tissue $\mathrm{Na}^{+}$Content or Lower $\mathrm{K}^{+}$Content?}

A key factor limiting plant growth in the case of salt stress, besides decreased water potential, is excessive $\mathrm{Na}^{+}$, which is a harmful element not required by most glycophytes for normal growth (Niu et al., 1995). High $\mathrm{Na}^{+}$tissue content is therefore often considered as the most critical factor responsible for salt toxicity in non-halophytes (Greenway and Munns, 1980; Niu et al., 1995). Our results with the sos mutants, however, indicated that salt sensitivity in Arabidopsis is not closely related with $\mathrm{Na}^{+}$tissue content (Figure 6). sos 1 plants take up less $\mathrm{Na}^{+}$and consequently have a lower $\mathrm{Na}^{+}$ content than do wild-type plants (Ding and Zhu, 1997), yet the lower $\mathrm{Na}^{+}$level is not associated with a reduced salt sensitivity in this mutant. In the rrs mutant of Arabidopsis that exhibits less sensitivity to $\mathrm{Na}^{+}$during germination, the $\mathrm{Na}^{+}$content is higher than in wild-type plants exposed to high external $\mathrm{NaCl}$ (Werner and Finkelstein, 1995). These observations do not support the notion that excess $\mathrm{Na}^{+}$is the primary cause of salt sensitivity in non-halophytes (Greenway and Munns, 1980).

In contrast, the results presented in Figure 6 indicate that the level of salt tolerance as measured by root growth correlates closely with $\mathrm{K}^{+}$content. Because of the critical role of $\mathrm{K}^{+}$homeostasis, relatively small variations in cellular $\mathrm{K}^{+}$ content are expected to cause large differences in plant
A

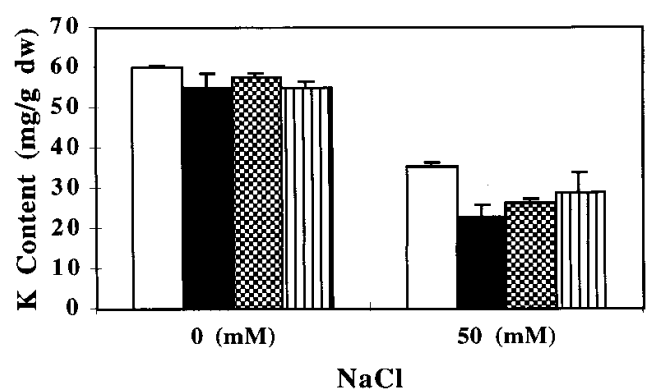

B

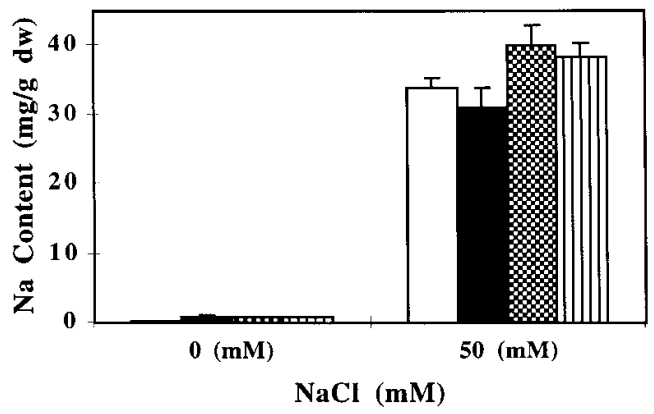

C

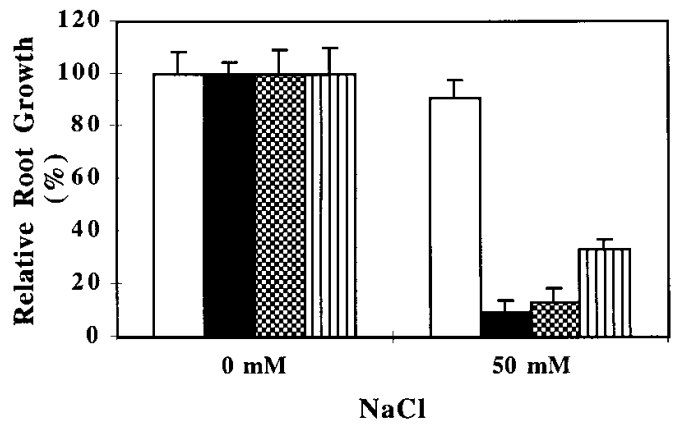

Figure 6. Salt Tolerance Correlates with $\mathrm{K}^{+}$Content but Not with $\mathrm{Na}^{+}$Content in Seedlings.

Five-day-old seedlings on MS agar plates were transferred to media (agar plates for root elongation measurement and liquid culture for $\mathrm{K}^{+}$and $\mathrm{Na}^{+}$assay) with or without $50 \mathrm{mM} \mathrm{NaCl}$ and allowed to grow for $48 \mathrm{hr}$. Open bars, wild type; black bars, sos1-1; stippled bars, sos2-1; striped bars, sos3-1; dw, dry weight.

(A) $\mathrm{K}^{+}$content in whole seedlings. Results are the average from three independent replicates. Error bars represent the standard deviation.

(B) $\mathrm{Na}^{+}$content in whole seedlings. Results are the average from three independent replicates. Error bars represent the standard deviation.

(C) Relative root growth. Error bars represent the standard deviation $(\mathrm{n}=15)$. 


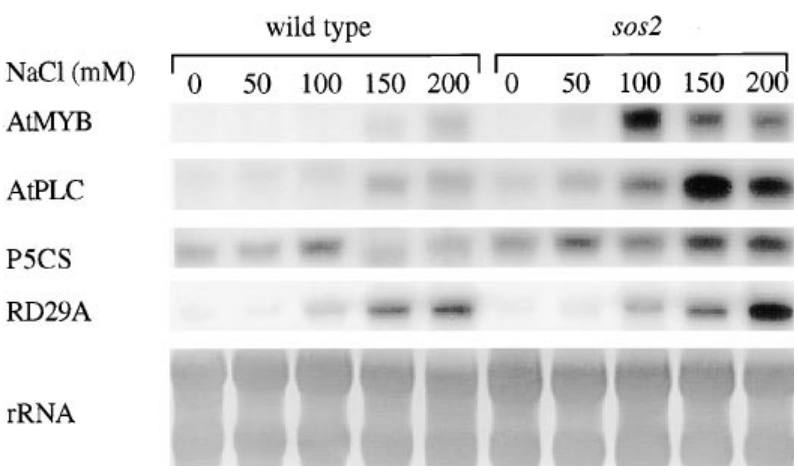

Figure 7. Salt Stress-Induced Gene Expression in Wild-Type and sos2-1 Seedlings Subjected to $\mathrm{NaCl}$ Treatment.

Expression of AtMYB and AtPLC genes was superinduced in sos2 seedlings.

growth. Because these plants are single-gene mutants and specifically sensitive to $\mathrm{Na}^{+}$, the results highlight the important role of $\mathrm{K}^{+}$nutrition in salt tolerance of this glycophytic plant. Several reports from studies with plant cell cultures and yeast cells have also suggested the importance of $\mathrm{K}^{+}$ nutrition in salt tolerance (Gorham et al., 1991; Watad et al., 1991; Gaxiola et al., 1992; Haro et al., 1993).

Mechanistically, $\mathrm{K}^{+}$nutrition is critical for $\mathrm{Na}^{+}$tolerance because $\mathrm{Na}^{+}$and $\mathrm{K}^{+}$are chemically very similar. High concentrations of external $\mathrm{Na}^{+}$inhibit $\mathrm{K}^{+}$absorption by plant roots, particularly through the low-affinity systems (Epstein, 1972). $\mathrm{K}^{+}$is an essential element that plays vital roles in various aspects of plant cell growth and metabolism and is needed in large quantities. Therefore, maintaining cellular $\mathrm{K}^{+}$content above certain threshold levels in the presence of excess external $\mathrm{Na}^{+}$is critical for plant growth and salt tolerance.

\section{Why Were Only Three SOS Loci Identified, and Why Are They All Involved in Potassium Nutrition?}

The large number of plants $(267,000)$ and primary mutagenized lines $(29,500)$ that we screened suggests that the sos mutant screening was nearly saturated. Altogether, 32 alleles of sos 1 and nine alleles of sos2 were found. The large numbers of sos 1 and sos2 alleles support the notion that the screening was close to saturation under the conditions used. The screening method is very effective in selecting mutants with great reduction in salt tolerance. However, mutants that are slightly more sensitive than the wild type are difficult to select with the present root-bending assay. This is probably why fewer sos 3 alleles were selected, because sos 3 is the least sensitive to $\mathrm{NaCl}$ among the three sos mutants.

Another constraint we put on the sos screening is that the mutants have to display relatively normal root bending (hence normal growth) in the absence of salt stress. There- fore, genes that are essential for both salt tolerance and normal plant growth were purposely excluded from our search. The constraint is necessary at the present time because it is still very difficult to distinguish between a gene essential only for normal growth and a gene essential for both normal growth and salt tolerance. Mutations in many housekeeping genes that have little to do with salt tolerance may result in decreased salt tolerance by reducing plant vigor.

Even considering these constraints, it is still surprising to find that the 42 sos mutants identified to date from near-saturated screening fall into only three complementation groups. Thus, only three SOS genes were found necessary for salt tolerance in Arabidopsis. Strictly speaking, only three genes were found that make large contributions to salt tolerance.

Even more surprisingly, all three SOS genes identified thus far turned out to be involved in potassium nutrition as well. We had expected to obtain mutants defective in $\mathrm{Na}^{+}$ extrusion or compartmentation, proline synthesis, expression of some salt-inducible genes, or osmotic signaling. These latter processes probably operate primarily at high concentrations of $\mathrm{NaCl}$. The accumulation of compatible osmolytes is often considered to be a universal protective mechanism used by many plants under salt stress. Whether proline accumulation is an adaptive process or a response to salt stress injury remains open to question (Bar-Nun and Poljakoff-Mayer, 1977; Hanson et al., 1979; Richards and Thurling, 1979; Moftah and Michel, 1987). The salt-hypersensitive sos1 mutant in fact accumulates more proline than does the wild type (Liu and Zhu, 1997a). It appears that at the level of $\mathrm{NaCl}$ stress seriously inhibitory for a sensitive

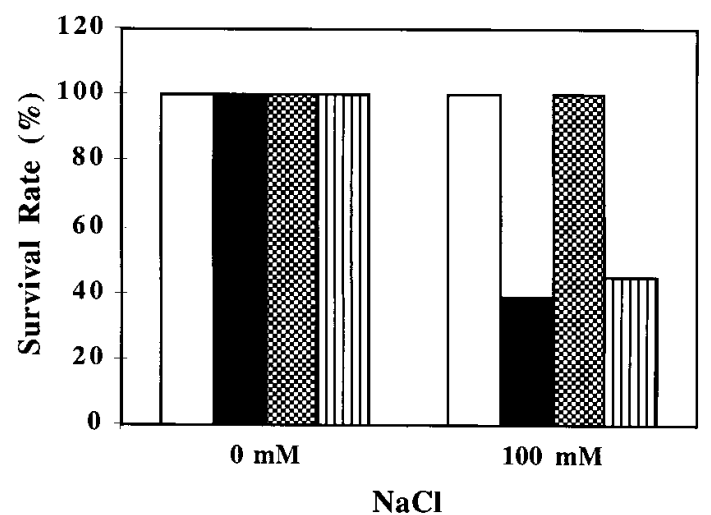

Figure 8. Comparison of Salt Sensitivity among sos1, sos2, and sos1 sos2 Double Mutants.

The sos 1 sos2 double mutant resembles sos 1 in salt tolerance. Seedlings were subjected to $100 \mathrm{mM} \mathrm{NaCl}$ treatment for 7 days, and the percentage of seedlings that survived the stress is presented. Seedling death was scored as complete bleaching of cotyledons and leaves. Fifty-six each of the wild-type and sos 1 seedlings, 59 sos 2 seedlings, and 63 sos 1 sos 2 double mutant seedlings were tested. Open bars, wild type; black bars, sos1; stippled bars, sos2; striped bars, sos 1 sos 2 double mutant. 
species like Arabidopsis $\left(<100 \mathrm{mM} \mathrm{NaCl}\right.$ ), intracellular $\mathrm{Na}^{+}$ toxicity or osmotic stress is still not a significant limiting factor. However, $\leqslant 100 \mathrm{mM} \mathrm{NaCl}$ does pose a serious problem for potassium nutrition, which is crucial for active growth. The fact that only these sos mutants were recovered suggests that although other processes such as $\mathrm{Na}^{+}$extrusion, $\mathrm{Na}^{+}$compartmentation, proline accumulation, and osmotic signaling may also be important, $\mathrm{K}^{+}$nutrition is the most critical process for salt tolerance in Arabidopsis.

We have shown here that impaired potassium nutrition accompanies increased salt sensitivity. Several reports have shown that improved $\mathrm{K}^{+}$nutrition correlates with increased salt tolerance (Gorham et al., 1991; Watad et al., 1991; Dvorak and Gorham, 1992; Gaxiola et al., 1992; Rubio et al., 1995). Perhaps under $\mathrm{NaCl}$ stress, only when $\mathrm{K}^{+}$nutrition is assured, will problems with other processes, such as maintaining a low cytoplasmic $\mathrm{Na}^{+}$content, accumulation of compatible solutes, and protective stress proteins, subsequently become more prominent. In this context, it is interesting to speculate that salt-tolerant plant species must possess very effective $\mathrm{K}^{+}$nutrition systems that are not disrupted by exposure to high external $\mathrm{Na}^{+}$.

\section{A Genetic Model of Salt Tolerance Mechanisms in Glycophytes}

Based on the results from the analysis of sos mutants, a genetic model for salt tolerance mechanisms in glycophytes can be outlined. In this model, $\mathrm{K}^{+}$nutrition is credited as a crucial cellular process and a key element for salt tolerance in Arabidopsis. The term $\mathrm{K}^{+}$nutrition is used here to refer loosely to a collection of $\mathrm{K}^{+}$-related activities, including influx, efflux, and utilization. Tracer uptake experiments using ${ }^{86} \mathrm{Rb}^{+}$have shown that sos 1 mutants clearly have a defect in $\mathrm{K}^{+}$uptake (Wu et al., 1996; Ding and Zhu, 1997). Similar experiments have failed to detect substantial differences in $\mathrm{K}^{+}$ uptake between sos3 and wild-type seedlings or excised roots (Liu and Zhu, 1997b) or between sos2 and wild-type seedlings or excised roots (data not shown). It is unclear whether sos 2 and sos3 plants are really not defective in $\mathrm{K}^{+}$ uptake or whether the results simply reflect the technical limitation of the uptake methodology. Notwithstanding, sos 2 and sos3 plants, like sos 1 , do exhibit $\mathrm{K}^{+}$deficiency under $\mathrm{NaCl}$ stress (Figure 6).

One possibility is that all three SOS genes encode regulatory components and not transporters. An Arabidopsis homo$\log$ of the wheat high-affinity $\mathrm{K}^{+} / \mathrm{Na}^{+}$cotransporter (Rubio et al., 1995) has been mapped recently. Evidence indicates that it is a single gene, and its map location does not correspond to any of the SOS genes (E. Kim and J. Schroeder, personal communication). Double mutant analysis (Figure 8; Liu and Zhu, 1997b) showed that the three SOS genes function in a linear pathway, although the epistatic relationship among the sos mutations cannot be ascertained because it is not known whether the mutant alleles are nulls. SOS3 likely encodes a $\mathrm{Ca}^{2+}$ sensor, which regulates $\mathrm{K}^{+}$nutrition (Liu and Zhu, 1997b). SOS1 is likely to be a general regulator of ion uptake because it has been found to play a role in $\mathrm{Na}^{+}$ as well as $\mathrm{K}^{+}$uptake (Ding and Zhu, 1997) and perhaps the uptake of several other cations ( . Liu and J .-K. Zhu, unpublished data). The proposed model is probably most relevant for low levels of salt stress ( $\leqslant 100 \mathrm{mM} \mathrm{NaCl}$ ). It does not exclude the functioning of additional mechanisms (e.g., $\mathrm{Na}^{+}$ extrusion and compartmentation) that may become important at higher levels of stress.

\section{METHODS}

\section{Plant Materials and Growth Conditions}

The ethyl methanesulfonate- or fast-neutron-mutagenized $M_{2}$ Arabidopsis thaliana seeds were obtained from Lehle Seeds (Round Rock, $\mathrm{TX}$ ) and were from ecotype Columbia carrying the homozygous recessive glabrous mutation (Koornneef et al., 1982). Agrobacterium tumefaciens-transformed lines (ecotype Wassilewskija) were obtained from K. Feldmann (Feldmann, 1991). The wild-type Arabidopsis Landsberg erecta ecotype used for genetic mapping was from the Arabidopsis Stock Center (Columbus, $\mathrm{OH}$ ).

Seeds were surface-sterilized in a solution of Clorox plus $0.1 \%$ Triton $\mathrm{X}-100$ for $10 \mathrm{~min}$ and rinsed five times with sterile water. The seeds were resuspended in sterile $0.4 \%[\mathrm{w} / \mathrm{v}]$ low-melting-point agarose before being sown in rows onto agar plates for germination. The agar medium contained Murashige and Skoog (MS) salts (Murashige and Skoog, 1962) with 3\% [w/v] sucrose and $1.2 \%[\mathrm{w} / \mathrm{v}]$ agar, $\mathrm{pH}$ 5.7. After $48 \mathrm{hr}$ at $4^{\circ} \mathrm{C}$ to improve germination uniformity, the plates were placed vertically in a growth room for germination. Mutant screening was conducted as previously described (Wu et al., 1996). When appropriate, seedlings (10 to 20 days old) were transferred to soil (Metro-Mix; Grace Sierra Horticultural Products Co., Milpitas, $\mathrm{CA}$ ) in pots and grown to maturity. The plants were watered twice a week with one-quarter strength Hoagland solution. Growth room temperature was $23^{\circ} \pm 2^{\circ} \mathrm{C}$. Light by cool-white fluorescent bulbs was 50 to $70 \mu \mathrm{E} \mathrm{m}^{-2} \mathrm{sec}^{-1}$ (constant) for seedlings in agar plates and $\sim 100 \mu \mathrm{E} \mathrm{m}^{-2} \mathrm{sec}^{-1}$ (16 hr of light and $8 \mathrm{hr}$ of dark) for potted plants.

\section{Genetic Analysis}

Backcrosses of sos mutants to the wild type and crosses among sos mutants were performed as described by Wu et al. (1996). $F_{1}$ and $F_{2}$ seedlings were scored for salt sensitivity by the root-bending assay (Wu et al., 1996). For mapping of the SOS2 locus, homozygous sos2-2 plants in the Columbia glabrousl (gl1) background were crossed to wild-type plants of the Landsberg erecta background. From the segregating $F_{2}$ generation, 624 homozygous sos mutants were selected, and DNA was extracted from each of these plants for mapping with molecular markers that are polymorphic between Columbia and Landsberg erecta.

To obtain a sos1 sos2 double mutant, 35 sos mutants were selected from the selfed $F_{2}$ progeny of a cross between sos2-1 sos2-1 and sos1-1 sos1-1. To identify a double mutant, these sos mutants were each testcrossed to sos2-1 sos2-1 and sos1-1 sos1-1. One 
double mutant line was identified because the $F_{1}$ progenies from both of the testcrosses showed a $\mathrm{NaCl}$-hypersensitive phenotype.

\section{Growth Measurements}

For growth measurements, 4-day-old seedlings from vertical agar plates were transferred to MS agar plates supplemented with various salts. The treatment plates were placed vertically with seedlings in the upright position. Three replicates were run for each treatment. Increases in root length were measured with a ruler every day for 7 days.

\section{Determination of $\mathrm{K}^{+}$and $\mathrm{Na}^{+}$Content}

Four-day-old seedlings on MS agar plates were transferred to $250-\mathrm{mL}$ flasks containing $50 \mathrm{~mL}$ of medium (half-strength MS salts and $2 \%$ sucrose, $\mathrm{pH}$ 5.5). The flasks were shaken at $120 \mathrm{rpm}$ at $22^{\circ} \mathrm{C}$ with continuous cool fluorescent light illumination. After 4 days, the appropriate amount of $5 \mathrm{M} \mathrm{NaCl}$ was added to give the desired $\mathrm{NaC}$ concentration, and the seedlings were allowed to continue growing for another $48 \mathrm{hr}$. The seedlings were then collected, rinsed briefly with distilled water, and dried at $65^{\circ} \mathrm{C}$ for $24 \mathrm{hr}$ and weighed. The samples were digested with $\mathrm{HNO}_{3}$, and the $\mathrm{K}^{+}$and $\mathrm{Na}^{+}$concentrations were determined with an atomic absorption spectrophotometer (model 560; Perkin-Elmer, Norwalk, CT).

\section{RNA Gel Blot Analysis}

Approximately 100 5-day-old seedlings were transferred from vertical MS plates to $250-\mathrm{mL}$ flasks containing $50 \mathrm{~mL}$ of half-strength MS solution and $2 \%[\mathrm{w} / \mathrm{v}]$ sucrose, $\mathrm{pH} 5.5$. The flasks were shaken at $120 \mathrm{rpm}$ under cool fluorescent light. After 2 days, an appropriate volume of $5 \mathrm{M} \mathrm{NaCl}$ was added to give the desired $\mathrm{Na}^{+}$concentration. Twelve hours later, the seedlings were collected from the flasks and frozen immediately in liquid nitrogen. The samples were ground in liquid nitrogen, and then RNA was extracted as described by Liu and Zhu (1997b). RNA was separated on formaldehyde-agarose gels and blotted onto a nylon membrane. The membrane was first stained with methylene blue to verify equal loading and transfer. Blots were then hybridized with ${ }^{32}$ P-labeled fragments of RD29A, P5CS, AtMYB, or AtPLC. The P5CS probe was a $1.6-\mathrm{kb}$ fragment showing sequence identity to the P5CS gene reported in Yoshiba et al. (1995). RD29A, AtMYB, and AtPLC probes were cloned from genomic DNA of wild-type Columbia plants by polymerase chain reaction. The RD29A fragment was a gene-specific $0.5-\mathrm{kb}$ probe from the $3^{\prime}$ noncoding region. Hybridizations were performed at $55^{\circ} \mathrm{C}$. Blots were washed at $55^{\circ} \mathrm{C}$ in $3 \times \mathrm{SSC}(1 \times \mathrm{SSC}$ is $0.15 \mathrm{M} \mathrm{NaCl}, 0.015 \mathrm{M}$ sodium citrate) (Ausubel et al., 1987) plus 0.1\% SDS.

\section{ACKNOWLEDGMENTS}

We thank Drs. Hans Bohnert, Robert Leonard, and Ray Bressan for helpful discussions and Lei Ding and Shaw-J ye Wu for excellent technical assistance. This work was supported by a grant from the U.S. Department of Agriculture National Research Initiative Competitive Grants to I .-K.Z.
Received April 14, 1998; accepted May 6, 1998.

\section{REFERENCES}

Ausubel, F.M., Brent, R., Kingston, R.E., Moore, D.D., Seidman, J .G., Smith, J .A., and Struhl, K., eds (1987). Current Protocols in Molecular Biology. (New York: J ohn Wiley and Sons).

Bar-Nun, N., and Poljakoff-Mayer, A. (1977). Salinity stress and the contents of proline in roots of $\mathrm{P}$ isum sativum and Tamarix teragyna. Ann. Bot. 41, 173-179.

Bell, C.J ., and Ecker, J .R. (1994). Assignment of 30 microsatellite loci to the linkage map of Arabidopsis. Genomics 19, 137-144.

Binzel, M.L., and Reuveni, M. (1994). Cellular mechanisms of salt tolerance in plant cells. Hort. Rev. 16, 33-69.

Bohnert, H.J ., Nelson, D.E., and J ensen, R.G. (1995). Adaptations to environmental stresses. Plant Cell 7, 1099-1111.

Bray, E.A. (1993). Molecular responses to water deficit. Plant Physiol. 103, 1035-1040.

Cushman, J.C., DeRocher, E.J ., and Bohnert, H.J . (1990). Gene expression during adaptation to salt stress. In Environmental Injury to Plants, F.J . Katerman, ed (New York: Academic Press), pp. 173-203.

Delauney, A.J ., and Verma, D.P.S. (1990). A soybean gene encoding $\Delta^{1}$-pyrroline-5-carboxylate reductase was isolated by functional complementation in Escherichia coli and is found to be osmoregulated. Mol. Gen. Genet. 221, 299-305.

Delauney, A.J ., and Verma, D.P.S. (1993). Proline biosynthesis and osmoregulation in plants. Plant J . 4, 215-223.

Ding, L., and Zhu, J --K. (1997). Reduced $\mathrm{Na}^{+}$uptake in the $\mathrm{NaCl}$ hypersensitive sos1 mutant of Arabidopsis thaliana. Plant Physiol. 113, 795-799.

Dvorak, J ., and Gorham, J . (1992). Methodology of gene transfer by homologous recombination into Triticum tugidum: Transfer of $\mathrm{K}^{+} / \mathrm{Na}^{+}$discrimination from $\mathrm{T}$. aestivum. Genome 35, 639-646.

Epstein, E. (1972). Mineral Nutrition in Plants: Principles and Perspectives. (New York: J ohn Wiley and Sons).

Epstein, E., Norlyn, J.D., Rush, D.W., Kingsbury, R.W., Kelly, D.B., Cunningham, G.A., and Wrona, A.F. (1980). Saline culture of crops: A genetic approach. Science 210, 399-404.

Feldmann, K.A. (1991). T-DNA insertion mutagenesis in Arabidopsis: Mutational spectrum. Plant J . 1, 71-82.

Gaxiola, R., de Larrinoa, I.F., Villalba, J .M., and Serrano, R. (1992), A novel and conserved salt-induced protein is an important determinant of salt tolerance in yeast. EMBO J . 11, 3157-3164.

Gorham, J., Bristol, A., Young, E.M., and Wyn J ones, R.G. (1991) Presence of the enhanced $\mathrm{K} / \mathrm{Na}$ discrimination trait in diploid Triticum species. Theor. Appl. Genet. 82, 729-736.

Greenway, H., and Munns, R. (1980). Mechanisms of salt tolerance in nonhalophytes. Annu. Rev. Plant Physiol. 31, 149-190.

Hanson, A.D., Nelson, C.E., Pedersen, A.R., and Everson, E.H. (1979). Capacity for proline accumulation during water stress in barley and its implications for breeding for drought resistance. Crop Sci. 19, 489-493. 
Haro, R., Baneulos, M.A., Quintero, F.J ., Rubio, F., and RodriguezNavarro, A. (1993). Genetic basis of sodium exclusion and sodium tolerance in yeast: A model for plants. Physiol. Plant. 89, 868-874.

Hasegawa, P.M., Bressan, R.A., and Handa, A.K. (1987). Cellular mechanisms of salinity tolerance. Hort. Sci. 21, 1317-1324.

Hirayama, T., Ohto, C., Mizoguchi, T., and Shinozaki, K. (1995). A gene encoding a phosphatidylinositol-specific phospholipase $C$ is induced by dehydration and salt stress in Arabidopsis thaliana. Proc. Natl. Acad. Sci. USA 92, 3903-3907.

Hu, C., Delauney, A.J ., and Verma, D.P.S. (1992). A bifunctional enzyme ( $\Delta^{1}$-pyrroline-5-carboxylate synthetase) catalyzes the first two steps in proline biosynthesis in plants. Proc. Natl. Acad. Sci. USA 89, 9354-9358.

Hurkman, W.J ., and Tanaka, C.K. (1987). The effects of salt on the pattern of protein synthesis in barley roots. Plant Physiol. 83, 517-524.

Iraki, N.M., Bressan, R.A., Hasegawa, P.M., and Carpita, N.C. (1989). Alteration of the physical and chemical structure of the primary cell wall of growth-limited plant cells adapted to osmotic stress. Plant Physiol. 91, 39-47.

J ones, M.M., and Turner, N.C. (1978). Osmotic adjustment in leaves of sorghum in response to water deficits. Plant Physiol. 61, 122-126.

Konieczny, A., and Ausubel, F.M. (1993). A procedure for mapping Arabidopsis mutations using co-dominant ecotype-specific PCRbased markers. Plant J . 4, 403-410.

Koornneef, M., Dellaert, L.W.M., and Van der Veen, J.H. (1982). EMS- and radiation-induced mutation frequencies at individual loci in Arabidopsis thaliana (L.) Heynh. Mutat. Res. 93, 109-123.

Liu, J., and Zhu, J.-K. (1997a). Proline accumulation and saltinduced gene expression in a salt-hypersensitive mutant of Arabidopsis. Plant Physiol. 114, 591-596.

Liu, J., and Zhu, J.-K. (1997b). An Arabidopsis mutant with increased calcium requirement for potassium nutrition and salt tolerance. Proc. Natl. Acad. Sci. USA 94, 14960-14964.

Locy, R.D., Chang, C.-C., Nielsen, B.L., and Singh, N.K. (1996). Photosynthesis in salt-adapted heterotrophic tobacco cells and regenerated plants. Plant Physiol. 110, 321-328.

McCure, K.F., and Hanson, A.D. (1990). Drought and salt tolerance: Towards understanding and application. Trends Biotechnol. 8, 358-362.

Moftah, A.E., and Michel, B.E. (1987). The effect of sodium chloride on solute potential and proline accumulation in soybean leaves. Plant Physiol. 83, 238-240.

Murashige, T., and Skoog, F. (1962). A revised medium for rapid growth and bioassays with tobacco tissue culture. Physiol. Plant. 15, 473-497.

Murphy, A., and Taiz, L. (1995). A new vertical mesh transfer technique for metal-tolerance studies in Arabidopsis: Ecotypic variation and copper-sensitive mutants. Plant Physiol. 108, 29-38.
Niu, X., Bressan, R.A., Hasegawa, P.M., and Pardo, J .M. (1995). Ion homeostasis in $\mathrm{NaCl}$ stress environments. Plant Physiol. 109, 735-742.

Rains, D.W. (1972). Salt transport by plants in relation to salinity. Annu. Rev. Plant Physiol. 23, 367-388.

Richards, R.A., and Thurling, N. (1979). Genetic analysis of drought stress response in rapeseed (Brassica campestris and B. napus). III. Physiological characters. Euphytica 28, 755-759.

Rubio, F., Gassmann, W., and Schroeder, J.I. (1995). Sodiumdriven potassium uptake by the plant potassium transporter HKT1 and mutations conferring salt tolerance. Science 270, 1660-1663.

Seemann, J ., and C ritchley, C. (1985). Effects of salt stress on the growth, ion content, stomatal behavior and photosynthetic capacity of a salt-sensitive species, Phaseolus vulgaris L. Planta 164, 151-162.

Serrano, R., and Gaxiola, R. (1994). Microbial models and salt stress tolerance in plants. Crit. Rev. Plant Sci. 13, 121-138.

Singh, N.K., Handa, A.K., Hasegawa, P.M., and Bressan, R.A. (1985). Proteins associated with adaptation of cultured tobacco cells to $\mathrm{NaCl}$. Plant Physiol. 79, 126-137.

Skriver, K., and Mundy, J . (1990). Gene expression in response to abscisic acid and osmotic stress. Plant Cell 2, 503-512.

Urao, T., Yamaguchi-Shinozaki, K., Urao, S., and Shinozaki, K. (1993). An Arabidopsis myb homolog is induced by dehydration stress and its gene product binds to the conserved MYB recognition sequences. Plant Cell 5, 1529-1539.

Watad, A.-E.A., Reinhold, L., and Lerner, H.R. (1983). Comparison between a stable $\mathrm{NaCl}$-selected Nicotiana cell line and the wild type. $\mathrm{K}^{+}, \mathrm{Na}^{+}$, and proline pools as a function of salinity. Plant Physiol. 73, 624-629.

Watad, A.-E.A., Reuveni, M., Bressan, R.A., and Hasegawa, P.M. (1991). Enhanced net $\mathrm{K}^{+}$uptake capacity of $\mathrm{NaCl}$-adapted cells. Plant Physiol. 95, 1265-1269.

Werner, J.E., and Finkelstein, R.R. (1995). Arabidopsis mutants with reduced response to $\mathrm{NaCl}$ and osmotic stress. Physiol. Plant. 93, 659-666.

Wu, S.-J ., Ding, L., and Zhu, J .-K. (1996). SOS1, a genetic locus essential for salt tolerance and potassium acquisition. Plant Cell 8, 617-627.

Yamaguchi-Shinozaki, K., and Shinozaki, K. (1993). Arabidopsis DNA encoding two desiccation-responsive $\mathrm{rd} 29$ genes. Plant Physiol. 101, 1119-1120.

Yancey, P., Lark, M., Hand, S., Bowlus, R., and Somero, G. (1982). Living with water stress: Evolution of osmolyte systems. Science 217, 1214-1222.

Yoshiba, Y., Kiyosue, T., Katagiri, T., Ueda, H., Mizoguchi, T., Yamaguchi-Shinozaki, K., Wada, K., Harada, Y., and Shinozaki, K. (1995). Correlation between the induction of a gene for $\Delta^{1}$-pyrroline-5-carboxylate synthetase and the accumulation of proline in Arabidopsis thaliana under osmotic stress. Plant J . 7, 751-760.

Zhu, J.-K., Hasegawa, P.M., and Bressan, R.A. (1997). Molecular aspects of osmotic stress in plants. Crit. Rev. Plant Sci. 16, 253-277. 